\title{
Embrace the Web!
}

BY MATTHIAS TOMCZAK

It is now ten years since I began to place my lecture notes on the World Wide Web. When I started it in 1996, I did it rather reluctantly, in response to personnel and funding pressures that resulted in "voluntary retirements" and increased teaching loads for the remaining staff. I saw placing my lecture notes on the web as a cheap way of managing overlapping teaching duties while trying to remain active in research.

When the wave of funding reductions began to have an impact on the tutor and demonstrator level and on our oceanography teaching laboratory, I re- made an entire textbook available on my web site. It was again a reaction to adverse conditions, this time to a bad experience with a commercial publisher.

Over the years, my site has grown into a respectable resource. It now includes animated demonstrations of oceanographic principles, photos of atmospheric and oceanic phenomena, output from numerical models, animations of El Niño years, and much more ${ }^{1}$. My web site has received praise from teachers and students of all continents. It has only one basic flaw: it was built as a reaction to adversity, not as an initiative

\section{...adopt the Internet as a normal part of everyday life, including university teaching.}

acted by designing interactive exercises. Rather than asking students to study static stability of a water column by filling a beaker with water of successively higher density, I placed them in front of computers and let them work on the same problem in virtual space.

When the Portable Document Format (PDF) became a universal standard, I

Matthias Tomczak (Matthias.Tomczak@ flinders.edu.au) is Professor of Oceanography, Flinders University, Adelaide, Australia. in innovation.

I realized the importance of this difference a few months ago when I heard about a survey undertaken by the Australian television and radio broadcaster SBS. The Special Broadcasting Service, set up by the government in 1978, is held by its charter "to provide multilingual and multicultural radio and television services that inform, educate, and entertain all Australians and, in doing so, re- 1http://www.es.flinders.edu.au/ mattom/ flect Australia's multicultural society."

A few months ago, SBS management had become concerned about the loss of penetration of the broadcaster's news and current affairs programs into younger audiences and had charged a consultant to investigate. When the consultant interviewed young people across the standard spread of social, economic, and intellectual conditions, the answers, varied as they were, had a common core: Young people use television and radio for entertainment; they switch off when the transmission moves to news and current affairs.

But - and this was the revelation for me-this action by young people does not mean that they are uninformed.

They simply do not trust the classic news media and turn to the Internet instead. Young people get their information from online resources that report what is happening first hand, not delivered by embedded or otherwise filtered journalism. They turn to web diaries and blogs and patch the picture together from many sources.

Before we deplore the negative attitude of young people towards information sources, many of us might consider respectable, let me remind you of my own time as a student in Germany. “Trau' keinem über dreißig”- - trust no one over thirty — was the slogan of the anti-authoritarian movement of the 
1970s. Being right and knowing better was and remains the prerogative of youth. Insisting on knowing better just because we are older does not get us anywhere. The art of teaching consists of my students' private lives changed my attitudes towards them, made me more responsive to questions and requests. But the main learning outcome for me was a totally new appreciation of the lives of

\section{It is not enough to direct students occasionally to a useful source of information on the web; the Internet has to become an integral part of our teaching.}

transmitting knowledge and experience through a process of dialogue and trust.

Intrigued by my discovery, I searched the Internet for the blogs of young people I knew and made another unexpected discovery. People who I had come to know as bright, well-performing students were describing problems of their lives, bouts of depression, imagined suicides through deliberate car crashes, actual suicide attempts, for everyone to read. Sometimes they received reassuring and supportive feedback from friends or other bloggers; often they remained on their own.

After an initial period of shock and insecurity about how to react, I decided that it was not my role to play the amateur psychologist and that the student counseling service was the more appropriate address. Maybe my discoveries of young people.

I always considered the Internet a great invention. It gives me as a scientist so many more possibilities: targeted search for publications I need for my own work, access to publications without the need to walk to the library, quick turnaround of correspondence with colleagues through email, and so forth. What I had not yet realized was that young people use the Internet in a very different way. For me, the Internet is a convenient library; for my students it is part of their lives, just as the washing machine and the telephone have been for me. For my students the normal world comes with the Internet; their lives would be unthinkable without it.

The consequence of my discovery is straightforward: if I want to connect with my students, if I do not want to be seen as a specimen of the weird academic world on the way to obsolescence, I have to change my attitude toward the web, and become part of the web community. There are many good things happening on the web. One of the best things is Wikipedia, the online encyclopedia. Wikipedia is unique in that it not only offers information on millions of topics in currently eleven languages, but allows everyone to add new information or edit existing entries.

As an academic with high professional standards, I was of course skeptical of an encyclopedia that can be edited by all and sundry. Isn't the Internet the meeting place for creationists, conspiracy theorists, and promoters of miracle drugs?

The science journal Nature compared 42 pairs of articles from Wikipedia and Encyclopeedia Britannica and found that the two information sources were of comparable value; both contained about the same amount of errors and omissions. When Nature published its finding in its 15 December 2005 issue ${ }^{2}$, the editors of Encyclopaedia Britannica objected vigorously. The reaction was not unexpected; after all, a free encyclopedia accessible through your laptop at any wireless hot spot in the country is serious competition for a traditional information medium. A demand to Nature to re-

2http://www.nature.com/nature/journal/v438/n7070/full/438890a.html 
tract the study followed and was rejected. In March 2006, Encyclopoedia Britannica refuted the Nature study in great detail ${ }^{3}$. It may satisfy its editors, but it will not provide a win in the long term; the young will continue to abandon printed media and turn to the Internet.
Isserman, Professor of History at Hamilton College, writes in his lecture notes: "Mail sent from England to the American colonies was taking a long time to arrive- two months on average. And yet merchant ships, which were heavier and took a longer route than the mail packet

\section{Your lectures can...be enmeshed with your students' online life, and low attendance rates may become a thing of the past.}

I now recommend Wikipedia ${ }^{4}$ to my students. Its administrators keep a very close watch and quickly eliminate malicious entries. The sciences-in contrast to areas such as history and politics-do not contain much controversial material, and the people who write entries are usually experts in their field. The entries for oceanography and its sub-disciplines are growing rapidly. We are all invited to contribute.

Access to this resource does not, of course, eliminate the need to educate students in the correct use of the Internet and teach them to verify the credibility of its content. (Has that not been true as well when we relied exclusively on printed books?) As an example that you should not trust a single source, I tell my students the story of my web search about how Benjamin Franklin became interested in studying the Gulf Stream. I found three versions, and to this day have not been able to establish which of them is the correct one: (1) Maurice including university teaching. It is not enough to direct students occasionally to a useful source of information on the web; the Internet has to become an integral part of our teaching.

How can we do that? As someone who just reached the Emeritus stage of life, I will not have the opportunity to introduce teaching innovations any more and am not exactly in a position to make suggestions. However, when I consider the outcome of the SBS study and my experience with student blogs, it appears to me that my first step would be to set up my own blog. I would use it to post my thoughts and convictions about oceanographic matters of general concern, about global warming, the world census of marine life, the attitude of governments to the establishment of marine parks, coastal protection, and whatever is topical in marine sciences at the moment. I would encourage my students to post their own thoughts in response to my blog entries and start a debate.

If you can generate a lively debate with blog entries related to science issues you may find that you can begin your lectures with a discussion of the latest blog entries. Your lectures can then be enmeshed with your students' online life, and low attendance rates may become a thing of the past.

The Internet will continue to change university teaching. We can be pushed into it by our students, or we can be part of the process and actively contribute to its evolution. ब्य

\footnotetext{
${ }^{3}$ http://corporate.britannica.com/britannica_nature_response.pdf

4http://www.wikipedia.org/

${ }^{5}$ http://www.studyofplace.com/Modules/Module.cfm?Moduleld=2\&Moduleltemld=7

${ }^{6}$ http://starryskies.com/articles/2003/10/gulf.stream.html

'http://coastalguide.com/bearings/gulfstream2.shtml
} 